\title{
Modelling Dowel Action of Discrete Reinforcing Bars in Cracked Concrete Structures
}

\author{
A.K.H. Kwan ${ }^{\mathrm{a}}$, P.L. Ng ${ }^{\mathrm{a}}$ *, and J.Y.K. Lam ${ }^{\mathrm{a}}$ \\ ${ }^{a}$ Department of Civil Engineering, The University of Hong Kong \\ *Email address for corresponding author: irdngpl@gmail.com
}

\begin{abstract}
Dowel action is one of the component actions for shear force transfer in cracked reinforced concrete. In finite element analysis of concrete structures, the use of discrete representation of reinforcing bars is considered advantageous over the smeared representation due to the relative ease of modelling the bond-slip behaviour. However, there is very limited research on how to simulate the dowel action of discrete reinforcing bars. Herein, a numerical model for dowel action of discrete reinforcing bars crossing cracks in concrete is developed. The model features the derivation of dowel stiffness matrix based on beam-on-elasticfoundation theory and the direct assemblage of dowel stiffness into the concrete element stiffness matrices. The dowel action model is incorporated in a nonlinear finite element programme with secant stiffness formulation. Deep beams tested in the literature are analysed and it is found that the incorporation of dowel action model improves the accuracy of analysis.
\end{abstract}

Keywords: Cracks; Dowel action; Finite element method; Reinforced concrete.

PACS: $46.70 . \mathrm{De}$

\section{INTRODUCTION}

Compared to the axial and flexural counterparts, the shear behaviour of concrete structures is less predictable due to the complexity of shear transfer mechanisms and the difficulties in numerical modelling, and yet it plays an important role in the overall structural behaviour of reinforced concrete members [1]. The dowel action of reinforcing bars is one of the component actions for shear transfer in a cracked concrete structure. According to Park and Paulay [1], the shear resistance of a cracked concrete structure is constituted of: (1) direct transfer of shear force by uncracked concrete; (2) direct tensile forces in stirrups; (3) aggregate interlock at crack surface; and (4) dowel action of reinforcing bars crossing the crack. Figure 1 shows the above internal forces pertaining to a cracked concrete beam.

Being a major component of the shear transfer in a cracked concrete structure, the dowel action of reinforcing bars has been investigated experimentally by many researchers [2-7]. However, despite decades of research on the finite element analysis of reinforced concrete structures, there has been basically no explicit consideration of the dowel action in finite element analysis. At the most, only a gross allowance with the dowel action lumped together with other components of shear transfer was incorporated [8]. It was only until more recently that the first author developed a dowel action model for application with smeared representation of reinforcing bars [9]. In this model, the dowel force and dowel deformation are expressed in smeared forms and the dowel stiffness matrix is assembled into the concrete element stiffness matrix. It has been applied to analyse deep beams and coupling beams [10,11].

The modelling of dowel action for smeared reinforcement is only an interim measure so as to be compatible with the existing finite element programs using smeared representation of the reinforcing bars. In the long run, for more realistic modelling of the bond-slip behaviour and dowel action of the reinforcing bars, discrete representation of the reinforcing bars should be adopted instead of smeared representation. With discrete representation, the reinforcing bars are modelled by discrete one-dimensional steel elements. To model the bond-slip behaviour of the reinforcing bars, the steel elements are connected to the concrete through bond elements. The most commonly used bond

CP1233 The $2^{\text {nd }}$ International ISCM Symposium and The $12^{\text {th }}$ International EPMESC Conference

J. W. Z. Lu, A.Y.T. Leung, V. P. Iu, and K. M. Mok

(C) 2010 American Institute of Physics 978-0-7354-0778-7/10/\$30.00 
element is the 4-noded interface element developed by Goodman et al. [12]. Each such bond element is assumed to have an infinitesimally small thickness. It has two pairs of duplicated nodes. The two nodes in each pair of duplicated nodes have the same coordinates but different degrees of freedom. Between them, one is connected to the steel reinforcement while the other is connected to the concrete. The difference in displacement of the duplicated nodes in the direction of the steel-concrete interface is taken as the slip.

Herein, a numerical method of incorporating the dowel stiffness of discrete reinforcing bar into the concrete element stiffness matrix is proposed.

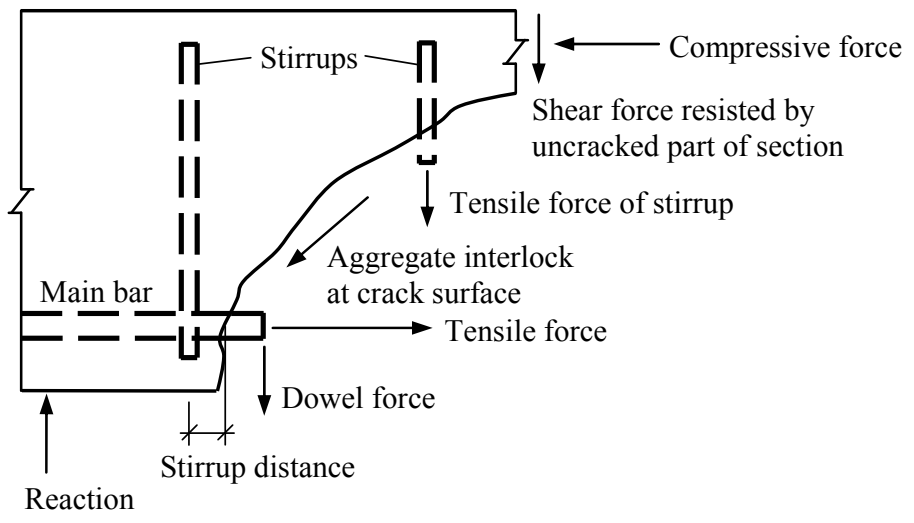

FIGURE 1. Internal forces in cracked beam

\section{MODELLING OF CONCRETE, STEEL REINFORCEMENT AND BOND}

To account for the biaxial behaviour of the concrete, the biaxial stress-strain relation is described in terms of equivalent uniaxial strains, and the tensile and compressive strengths in the principal directions are determined using the biaxial strength envelope developed by Kupfer and Gerstle [13]. For any principal direction under tension, the stress-strain curve proposed by Guo and Zhang [14] is adopted. For any principal direction under compression, the stress-strain curve proposed by Saenz [15] is adopted. From the stress-strain curves, the secant stiffness values in the two principal directions $E_{c 1}$ and $E_{c 2}$ are evaluated and used to derive the constitutive matrix of concrete [ $\left.D_{c}^{\prime}\right]$ in the local coordinate system [16]:

$$
\left[D_{c}^{\prime}\right]=\frac{1}{1-v_{1} v_{2}}\left[\begin{array}{ccc}
E_{c 1} & v_{2} E_{c 1} & 0 \\
v_{1} E_{c 2} & E_{c 2} & 0 \\
0 & 0 & \left(1-v_{1} v_{2}\right) G
\end{array}\right]
$$

where $v_{1}$ and $v_{2}$ are the Poisson's ratios in two principal directions and $G$ is the shear modulus. Before cracking, the shear modulus is taken as the initial elastic shear modulus $G_{0}$. After cracking, the shear modulus is taken as $\gamma G_{0}$, in which $\gamma$ is the shear retention factor to account for the aggregate interlock effect.

The elastic, plastic and strain hardening behaviour of the steel reinforcement is modelled by an appropriate stressstrain curve, based on which the secant stiffness of the steel reinforcement $E_{s}$ is evaluated and the constitutive matrix of steel $\left[D_{s}^{\prime}\right]$ in the local coordinate system is derived as:

$$
\left[D_{s}^{\prime}\right]=\left[\begin{array}{ccc}
E_{s} & 0 & 0 \\
0 & 0 & 0 \\
0 & 0 & 0
\end{array}\right]
$$

For the bond between the steel reinforcement and concrete, the bond stress-slip relation recommended by Model Code 1990 [17] is employed. The secant bond stiffness is evaluated as the bond stress to bond slip ratio and the stiffness matrix of bond element in the local coordinate system is derived with the area of interface taken as the length of bond element times the total perimeter of steel reinforcement.

From the above derived stiffness matrices in the local coordinate system, the corresponding stiffness matrices in the global coordinate system are obtained by coordinate transformation. 


\section{DOWEL FORCE-DISPLACEMENT RELATIONSHIP}

Let the dowel force be denoted by $V_{d}(\mathrm{kN})$ and the dowel displacement be denoted by $\Delta_{d}(\mathrm{~mm})$. The relationship between $V_{d}$ and $\Delta_{d}$ has been derived from experimental results $[2,3,6]$. Herein, the linearly elastic-perfectly plastic dowel force-displacement relation derived by He and Kwan [9] is adopted. Mathematically, it is given by:

$$
\begin{array}{llll}
V_{d}=k_{d 0} \Delta_{d} & \text { for } & \Delta_{d} \leq \Delta_{d o} \\
V_{d}=V_{d o} & \text { for } & \Delta_{d}>\Delta_{d o}
\end{array}
$$

where $k_{d o}$ is the initial dowel stiffness, $V_{d o}$ is the peak dowel force (or dowel strength), and $\Delta_{d o}$ is the dowel displacement at peak dowel force, $\Delta_{d o}=V_{d o} / k_{d 0}$.

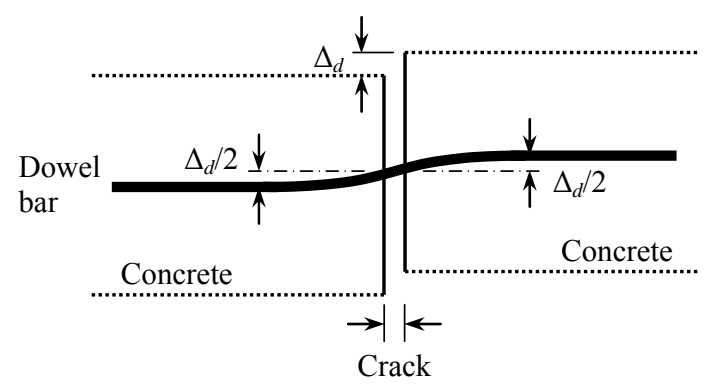

(a) Contraflexural deformation of dowel bar against elastic foundation

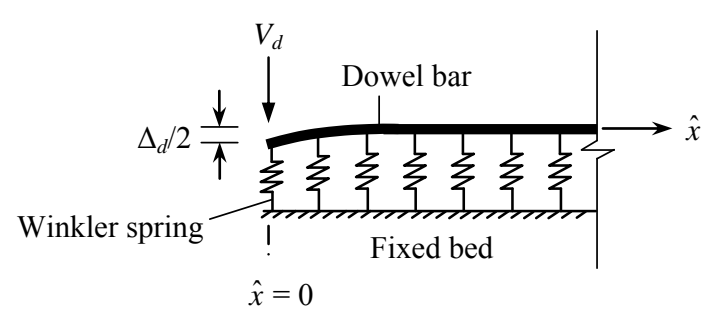

(b) Modelling of elastic foundation by Winkler springs

FIGURE 2. Visualisation of dowel action as beam on elastic foundation

The dowel stiffness $k_{d}(\mathrm{kN} / \mathrm{mm})$ is established based on the beam-on-elastic-foundation theory with the reinforcing bar treated as a beam to deal with the interaction between the reinforcing bar and the surrounding concrete. According to the beam-on-elastic-foundation theory, the foundation may be treated as a bed of Winkler springs so that the reaction force from the foundation at any point may be assumed to be proportional to the deflection of the beam at that point. Cutting the reinforcing bar subjected to dowel action at the point of contraflexure, the bar may be treated as a semi-infinite beam resting on the foundation subjected to concentrated load at one end, as shown in Figure 2. From the analytical solutions of the beam-on-elastic-foundation problem [18], the relationship between the deflection of dowel bar at any point $\Delta_{\hat{x}}$ and the concentrated dowel force can be derived as

$$
\Delta_{\hat{x}}=\frac{V_{d}}{E_{s 0} I_{s} \lambda_{f}^{3}} \exp \left(-\lambda_{f} \hat{x}\right) \cdot \cos \left(\lambda_{f} \hat{x}\right)
$$

where $\hat{x}$ is the distance of the point being considered from the dowel force, $E_{s 0}$ is the initial elastic modulus of steel, $I_{s}$ is the moment of inertia of the bar (for a reinforcing bar with diameter $\phi_{s}, I_{s}$ is equal to $\pi \phi_{s}^{4} / 64$ ), $\lambda_{f}$ is a parameter $\left(\mathrm{mm}^{-1}\right)$ representing the relative stiffness of the foundation (i.e. the surrounding concrete), as given by:

$$
\lambda_{f}=\sqrt[4]{\frac{k_{f} \phi_{s}}{4 E_{s 0} I_{s}}}
$$

In Equation (5), $k_{f}(\mathrm{MPa} / \mathrm{mm})$ is the foundation modulus of the surrounding concrete. The following data-fitting expression for $k_{f}$ proposed by Soroushian et al. [19] is used:

$$
k_{f}=\frac{127 c_{f} \sqrt{\left|f_{c}\right|}}{\phi_{s}^{2 / 3}}
$$

where $c_{f}$ is a coefficient ranging from 0.6 for a clear bar spacing of $25 \mathrm{~mm}$ to 1.0 for larger bar spacing, and $f_{c}$ is the uniaxial compressive strength of concrete.

Equations (4) and (5) represent classical solution for the problem of beam-on-elastic-foundation, where flexural but not shear deformation of the beam is considered. For the case of steel bars embedded in concrete, shear deformation of bars is sufficiently small to be neglected. Substitute $\hat{x}=0$ into Equation (4), the relationship between the dowel force and the dowel displacement under elastic condition is obtained as

$$
V_{d}=E_{s 0} I_{s} \lambda_{f}{ }^{3} \Delta_{d}
$$


from which the initial dowel stiffness may be derived as

$$
k_{d 0}=E_{s 0} I_{s} \lambda_{f}{ }^{3}
$$

The peak dowel force $V_{d o}$ is evaluated using the expression by Vintzeleou and Tassios [4]:

$$
V_{d o}=1.3 \phi_{s}^{2} \sqrt{\left|f_{c} \cdot f_{y}\right|}
$$

where $f_{y}$ is the yield strength of dowel bar.

With Equations (3), (8) and (9), the dowel force-displacement relationship is well-defined. To formulate the dowel stiffness matrices, the secant dowel stiffness $k_{d}$ is evaluated as per Equation (8) if the dowel action is linearly elastic, and is evaluated as $V_{d o} / \Delta_{d}$ if the dowel action becomes plastic.

\section{MODELLING OF DOWEL ACTION}

Herein, it is proposed to incorporate the dowel stiffness of the steel bar elements into the adjoining concrete elements so that the steel elements do not need to have rotational degrees of freedom. This is done by identifying the concrete elements adjoining the steel element (for each steel element, there shall be two adjoining concrete elements), and then superimposing the dowel stiffness matrix $\left[K_{d i}\right](i=1,2)$ onto the stiffness matrices of these concrete elements. The dowel stiffness matrix is devised based on the energy principle, as depicted hereunder.

The work done $U_{d}$ to cause the dowel deformation may be represented as:

$$
U_{d}=0.5 \Delta_{d} \cdot\left(k_{d} \Delta_{d}\right)
$$

The energy associated with the work done is distributed over the two concrete elements adjoining each steel element on a pro-rata area basis. Let $\alpha_{d i}(i=1,2)$ be the distribution coefficient such that for the two concrete elements whose areas are $A_{1}$ and $A_{2}, \alpha_{d 1}=A_{1} /\left(A_{1}+A_{2}\right)$ and $\alpha_{d 2}=A_{2} /\left(A_{1}+A_{2}\right)$. The strain energy $U_{d i}(i=1,2)$ imparted in each concrete element is expressed as:

$$
U_{d i}=0.5 \alpha_{d i} \cdot \Delta_{d} \cdot\left(k_{d} \Delta_{d}\right)
$$

Denoting the strain matrix of the adjoining concrete element by $[B]_{i}(i=1,2)$, the dowel stiffness matrix is given by:

$$
\left[K_{d i}\right]=[B]_{i}^{T}\left[T_{\Delta}\right]^{T}\left(\alpha_{d i} \cdot k_{d} \cdot \ell_{s}^{2}\right)\left[T_{\Delta} \llbracket[B]_{i}\right.
$$

where $\ell_{s}$ is the length of steel bar element and $\left[T_{\Delta}\right]$ is the transformation matrix of dowel displacement, defined by:

$$
\left[T_{\Delta}\right]=\left[\begin{array}{ccc}
c^{2} & s^{2} & c s \\
s^{2} & c^{2} & -c s \\
-2 c s & 2 c s & c^{2}-s^{2}
\end{array}\right]
$$

with $c$ and $s$ denoting respectively the cosine and sine of the angle between axial direction of reinforcement and global $x$-direction.

It should be noted from Equation (12) that the concrete element shape function has been integrated into the dowel stiffness matrix. Hence, the dowel stiffness of reinforcing bars can be directly assembled into the concrete element stiffness matrix.

\section{APPLICATIONS TO THE ANALYSIS OF DEEP BEAMS}

The reinforced concrete deep beams analysed include the Specimens NNN-1 and NHN-1 tested by Xie et al. [20]. These two deep beams have been analysed by He [10] based on the smeared reinforcement and smeared crack approaches. A sketch of the beams is depicted in Figure 3. The deep beam specimens belonged to the same test series and they have similar configurations.

The two deep beam specimens have uniform cross-section of $127.0 \mathrm{~mm}$ breadth by $254.0 \mathrm{~mm}$ depth and the effective depth is $215.9 \mathrm{~mm}$. They are subjected to single point loads at mid-span position. The shear span to effective depth ratio is fixed at 1.0. NNN-1 is cast of normal-strength concrete $\left(f_{c}=44.6 \mathrm{MPa}\right)$; whereas $\mathrm{NHN}-1$ is cast of high-strength concrete $\left(f_{c}=98.6 \mathrm{MPa}\right)$. The beams are singly reinforced with tension steel ratio of $1.8 \%$. Yield stress of reinforcement is $420.6 \mathrm{MPa}$. The elastic modulus, strain at start of strain hardening, ultimate tensile strength and ultimate strain of reinforcing steel are taken as $200 \mathrm{GPa}, 1 \%, 740 \mathrm{MPa}$ and 12\%, respectively. 


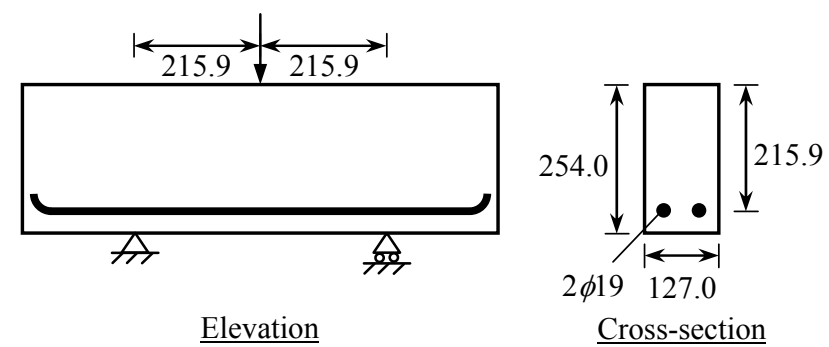

FIGURE 3. Geometric dimensions of deep beam specimens

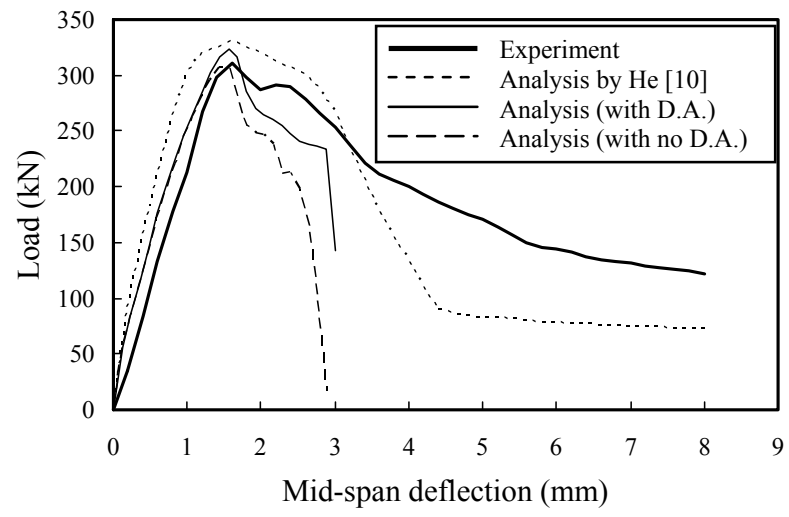

(a) Specimen NNN-1

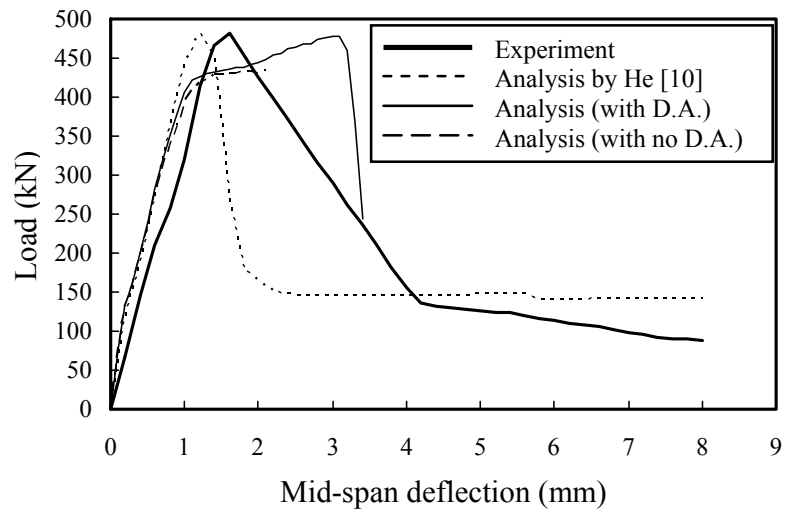

(b) Specimen NHN-1

FIGURE 4. Load-deflection curves of deep beam specimens (D.A. denotes dowel action)

Based on the proposed numerical model for dowel action of discrete bars, the deep beams are analysed with dowel action accounted for. The load-deflection curves of deep beam Specimens NNN-1 and NHN-1 are presented in Figure 4. In the same figure, the analytical curves by $\mathrm{He}[10]$ are presented.

The deep beams are re-analysed with the exclusion of dowel action, and the resulting load-deflection curves are depicted in Figure 4. It can be observed that when the dowel action is neglected, the computed peak load is slightly lower, and the shear ductility of beams is impaired. Moreover, the deviations from the experimental curves are aggravated. It can be concluded that in the numerical analysis of shear critical beams, the incorporation of dowel action in the structural modelling is certainly desirable.

\section{CONCLUSIONS}

In the finite element analysis of concrete structures, discrete representation of reinforcing bars is a more realistic way to reflect the interaction between concrete and reinforcement as compared to smeared representation. A new strategy for modelling the dowel action of discrete reinforcing bars has been devised in this study. Based on the energy principle and the beam-on-elastic-foundation theory, the dowel stiffness matrix and the dowel forcedisplacement relationship have been formulated. Since the dowel stiffness can be incorporated directly into the concrete elements, no special type of finite element for dowel action is required. The proposed dowel action model has been applied to analyse reinforced concrete deep beams. Numerical results have verified that the proposed dowel action model could improve prediction of the full range load-deflection behaviour of shear critical concrete members. The results have also correctly reflected the enhancement in shear ductility of deep beams by incorporation of dowel action, which constitutes one of the major components of shear resistance in post-peak regime. 


\section{REFERENCES}

1. R. Park and T. Paulay, Reinforced Concrete Structures, New York: John Wiley \& Sons, 1975, 769pp.

2. H. Dulacska, "Dowel action of reinforcement crossing cracks in concrete", ACI Journal 69(12), 754-757 (1972).

3. S. G. Millard and R. P. Johnson, "Shear transfer across cracks in reinforced concrete due to aggregate interlock and dowel action", Magazine of Concrete Research 36(126), 9-21 (1984).

4. E. N. Vintzeleou and T. P. Tassios, "Behavior of dowels under cyclic deformations", ACI Structural Journal 84(1), 18-30 (1987).

5. S. Dei Poli, M. Di Prisco and P. G. Gambarova, "Shear response, deformations, and subgrade stiffness of a dowel bar embedded in concrete", ACI Structural Journal 89(6), 665-675 (1992).

6. S. Dei Poli, M. Di Prisco and P. G. Gambarova, "Cover and stirrup effects on the shear response of dowel bar embedded in concrete", ACI Structural Journal 90(4), 441-450 (1993).

7. S. S. Mannava, T. D. Bush and A. R. Kukreti, "Load-deflection behavior of smooth dowels", ACI Structural Journal 96(6), 891-898 (1999).

8. ASCE Task Committee on Finite Element Analysis of Reinforced Concrete Structures, State-of-the-Art Report on Finite Element Analysis of Reinforced Concrete Structures, American Society of Civil Engineers, New York, 1982, 545pp.

9. X. G. He and A. K. H. Kwan, "Modeling dowel action of reinforcement bars for finite element analysis of concrete structures", Computers and Structures 79(6), 595-604 (2001).

10. X. G. He, "Constitutive Modeling of Reinforced Concrete for Nonlinear Finite Element Analysis", Ph.D. Thesis, The University of Hong Kong, 1999, 217pp.

11. Z. Z. Zhao, A. K. H. Kwan and X. G. He, "Nonlinear finite element analysis of deep reinforced concrete coupling beams", Engineering Structures 26(1), 13-25 (2004).

12. R. E. Goodman, R. L. Taylor and T. L. Brekke, "A model for the mechanics of jointed rock", Journal of the Soil Mechanics and Foundations Division, ASCE 94(3), 637-659 (1968).

13.H. B. Kupfer and K. H. Gerstle, "Behavior of concrete under biaxial stresses", Journal of the Engineering Mechanics Division, ASCE 99(4), 853-866 (1973).

14. Z. H. Guo and X. Q. Zhang, "Investigation of complete stress-deformation curves for concrete in tension", ACI Materials Journal 84(4), 278-285 (1987).

15. L. P. Saenz, "Discussion of the paper 'Equation for the stress-strain curve of concrete' by Prakash Desayi and S. Krishman", ACI Journal 61(9), 1229-1235 (1964).

16. D. Darwin and D. A. Pecknold, "Nonlinear biaxial stress-strain law for concrete", Journal of the Engineering Mechanics Division, ASCE 103(2), 229-241 (1977).

17. Comite Euro-International du Beton, CEB-FIP Model Code 1990: Model Code for Concrete Structures, London: Thomas Telford, 1993, 437pp.

18. M. I. Hetényi, Beams on Elastic Foundation: Theory with Applications in the Fields of Civil and Mechanical Engineering, Ann Arbor: The University of Michigan Press, 1958, 256pp.

19. P. Soroushian, K. Obaseki and M. C. Rojas, "Bearing strength and stiffness of concrete under reinforcing bars", ACI Materials Journal 84(3), 179-184 (1987).

20. Y. L. Xie, S. H. Ahmad, T. J. Yu, S. Hino and W. Chung, "Shear ductility of reinforced concrete beams of normal and highstrength concrete", ACI Structural Journal 91(2), 140-149 (1994). 
Copyright of AIP Conference Proceedings is the property of American Institute of Physics and its content may not be copied or emailed to multiple sites or posted to a listserv without the copyright holder's express written permission. However, users may print, download, or email articles for individual use. 